\title{
Crime and adolescent drug use in Lagos, Nigeria
}

\begin{abstract}
Mega cities are the common loci of youth-induced criminal activities. Yet, prior studies have not captured all causes and solutions. This study examines the influence of drug abuse on adolescent criminality in Lagos, Nigeria. It used quantitative and qualitative methods. Administered copies of a questionnaire to 150 respondents selected through a multistage sampling procedure from the randomly selected local government areas (LGAs) in urban, semi-urban, and rural communities of Lagos. Quantitative data were analyzed at various levels and qualitative data were content analyzed. Results showed a negative relationship between the fear of police and ever committed crime $\left(-.381^{* *}\right)$. Potential criminals who used drugs did not see the police as deterrent models. This facilitates crime commission. Those whose parents used drugs $\left(.159^{* *}\right)$ and the time drug consumption started $(.162 * *)$ are significant. The study concluded that drug abuse induced predatory crimes are common among adolescents. It advises government to involve social workers in the management of adolescents' drug abuserelated misconduct right from the family level.
\end{abstract}

Research Article

Volume 2 Issue 2 - 2018

\author{
Ayodele Johnson Oluwole, ' Adeleke Kazeem \\ Habibat, ${ }^{2}$ Gandonu M Babatunde ${ }^{3}$ \\ 'Department of Sociology, Lagos State University, Nigeria \\ 2Department of Human Resource Management, University of \\ Salford, United Kingdom \\ ${ }^{3}$ Department of Psychology, Lagos State University, Nigeria
}

Correspondence: Ayodele Johnson Oluwole, Department of Sociology, Lagos State University, Nigeria, Tel 0803352 I4I2,

Email johnson.ayodele@lasu.edu.ng

Received: August 25, 2017 | Published: March 06, 2018

\section{Introduction}

Africa has an annual growth of over 3 percent; the youth is estimated to reach 258 million by the year 2025. The 15-24 age group constitutes about 20 percent of the total population of the continent. ${ }^{1,2}$ These statistics make youth occupy a sensitively significant place in the population structure of Lagos. Since empirical evidences support the claims that drugs are used and abused by youth from all socio-economic and racial/ethnic backgrounds, drug abuse is linked to social problems such as child neglect, poverty, social pressures and traumas, crime and HIV/AIDS. ${ }^{3-7}$ Therefore, the relationship between adolescents, drug use and criminal behaviour is a source of concern for policymakers, researchers and the Nigerian public. It is not surprising therefore that policymakers assume that an important connection exists between drug use and crime. ${ }^{8}$ Policy makers assuming that an important connection exists between drug use and crime, ${ }^{8}$ did not, therefore, come as a surprise. Though the concept of drug may evoke different meanings to different people, usually, a drug is any substance other than food and water due to its chemical components, which when taken into the body alters the structure and function of the body. ${ }^{9}{ }^{10}$ Nevertheless, a number of views have been advanced about what constitutes substance abuse when considering adolescents. ${ }^{11}$ Essentially, drugs become abused when they are used in excessive, maladaptive, or addictive way for non-medicinal purposes. Drug abuse defines a state, emotional and sometimes physical, characterized by a compulsion to take drugs on a constant basis in order to experience its mental effects. ${ }^{12,13}$ adolescent drug abuse is the frequent use of alcohol or other drugs during the teenage years or the use of alcohol or other drugs in a manner that is associated with problems and dysfunctions. In this paper, adolescent drug abuse refers to the use of a licit and illicit drug in ways that deviate from the norms of its usage in a group or society, if the self-administration is judged to be harmful or excessive. This pattern of usage is usually identified on the basis of quantity taken, frequency of use and the context or social situation in which the drug is taken. ${ }^{14-17}$

Primarily, crime refers to a predatory crime that encompasses both violent and property crimes. ${ }^{18}$ It is expected that the use of any stimulant (e.g., cocaine, crack cocaine, methamphetamine, or amphetamines) will be in line with substance-related crimes, owing to its pharmacological properties.$^{19}$ In particular, stimulants are highly reinforcing, ${ }^{20-22}$ and drug users may become involved in the criminal justice system because of an arrest for a substance-related crime, such as possession or driving while intoxicated. Since stimulant use and criminality are highly associated, ${ }^{23}$ investigating the nexus between adolescent drug abuse and criminality is appropriate at this time. The phenomenal demographic change, which the Lagos currently experiences, makes this study justifiable. Adolescent drug abuse has both personal and social costs to individuals and the society. The effect has become so pronounced that drug abuse is involved in one third to one half of lung cancer and coronary heart disease cases in adults. Alcohol and other drugs are major factors in acquired immunodeficiency syndrome (AIDS), violent crimes, child abuse and neglect, and unemployment. ${ }^{24}$ In addition, drug abuse results to gang formation, cultism, armed robbery, mental illness etc. Studies revealed that most of the drug addicts started smoking from their adolescence. As they grow older they seek new thrills and gradually go into hard drugs. ${ }^{25}$ For the society at large, adolescent substance abuse extracts a high cost in health care, educational failure, mental health services, drug and alcohol treatment, and juvenile crime ${ }^{13}$ For the reason, therefore, that stimulant use and criminality are highly associated, ${ }^{23}$ the urge of adolescents to try out new discoveries could make their drug use have dire implications for social order in society. Nevertheless, the problems associated with drug abuse carry costs in lost productivity, lost life, destruction of families, and a weakening of the bonds that hold the society together. ${ }^{13}$

In a study of five selected psychiatric hospitals, Obot and Olaniyi (1991) show that drug related cases have increased since 1985. In a related study, Ikwuagwu et al. (1993) found that about 60 percent of substance abusers are young persons. Other studies such as Ikwuagwu et al. (1993) observe the worrisome preponderance of young persons in hospitals for alcohol and drug problems. The effects of drug abuse on an individual therefore form the basis for its cumulative effects on the society. This is the major danger of drug abuse. ${ }^{12}$ In spite of general decreases in the prevalence of the nonmedical use of most legal and 
illegal drugs in recent years, the abuse of alcohol and other drugs during adolescence and early adulthood remains a serious public health problem. ${ }^{26}$ Though drug abuse is a global health and social problem, ${ }^{27}$ its effects are felt in the unpleasant youthful activities that are widespread all over Lagos, Nigeria. It is against this background that this study attempted to provide answers to the following questions: (i) Why do adolescents abuse drugs? (ii) What are the implications of drug abuse for public safety in Lagos? (iii) How can the effects of adolescent drug abuse be addressed in society? In addition to sub-cultural and lifestyle explanations, it has been proposed that deviant individuals may use drugs in order to self-medicate ${ }^{28}$ or to give themselves an excuse to act in a deviant manner. ${ }^{29}$ Substance use and crime may be causally linked and mutually reinforcing and, thus, drinking and drug use may lead to more criminal behaviour and criminal behaviour may lead to more drinking and drug use. ${ }^{30}$ The common cause model assumes that substance use and crime do not have a direct causal link. Rather, they are related because they share common causes (such as genetic or temperamental traits, antisocial personality disorder, parental alcoholism, and poor relations with parents. ${ }^{31,32}$ Judging therefore from the foregoing, the exploration of both sub-cultural and common cause models provides an explanation for the drug-crime connection.

\section{Methods}

The study location was Lagos. The survey covered all the statutory 20 Local Government Areas of the state. Major bus stops, night clubs, beer parlours at which drug users live their daily lives in every local government area of Lagos served as recruitment cites for the 150 respondents on whom copies of the questionnaire for this study were administered. The study area was chosen for its level of urbanization and diverse characteristics. The New York Times estimates that Lagos is now at least twenty-one million, surpassing Cairo as Africa's largest city, making Lagos the largest city in Africa. ${ }^{33}$ It is clear that whatever the size, and however the city is defined, Lagos is the centre of one of the largest urban centers in the world. With a population of perhaps 1.4 million in 1970, its growth, ever since, has been amazing. Though, Lagos generates about a quarter of Nigeria's total gross domestic product, in the face of oil subsidy politics, the centre of Nigeria's modern economy, Lagos has many millionaires, while approximately two thirds of the population are slum dwellers. ${ }^{34}$

Both qualitative and quantitative methods were used for data gathering. For quantitative data, the questionnaire method was used and for qualitative, in-depth interview was used for data collection. Snowball sampling technique was used to select respondents. The specific interest of this study is directed at a target population. Individuals in a target population typically share one characteristic. Target population members are not usually available. ${ }^{35}$ Lagos being populated by an admixture of individuals that are mostly traditional and a few educated, the undesirable outcomes of drug use provoke stigmatization. The use of drug is prevalent among the elite members and their children who could afford the luxury. It is only in very rare cases when the drug use by the children of the poor are facilitated by their rich peers that they gatecrash into the practice of drug use because drugs are expensive. In this connection, this study selected the study site purposively. It selected its respondents through a multistage sampling procedure from the local government areas (LGAs) in urban, semi-urban, and rural communities from Lagos. In the first stage, a simple random sampling technique was used to select 1 LGA from each of the 3 senatorial districts, giving a total of 3 LGAs. In the second stage, based on existing data about areas considered the 'storehouse' of drugs in Lagos in each of the 3 selected LGAs were randomly selected. In stage three, five wards in Mushin LGA were included, 5 of the wards from Lagos Island LGA were randomly selected, and 5 wards were randomly selected from Ibeju Lekki LGA in the randomly selected LGAs. In the final stage, from each of the 5 political wards that were randomly selected from Mushin, and Lagos Island LGAs, 1 street was selected randomly. From the 5 political wards that were randomly selected from Ibeju Lekki LGA, 5 communities were randomly selected. Overall, 10 streets and 5 communities were randomly selected. One household was randomly selected from each of the selected 10 houses making 50 houses from Mushin LGA, 50 houses from Lagos Island LGA, and 50 houses from Ibeju Lekki LGA. The sum of these equals 150 houses. However, in a case where more than one family occupied a house, a lottery method (yes/no) was used to select the respondent interviewed. Copies of a questionnaire were given to the heads of each the 150 households. In addition to empirical data collected through quantitative and qualitative approaches, available materials were reviewed for related information. For the study, three categories of respondents were purposively selected for five in-depth interviews: a male police officer, a male head of key community vigilante groups and a male chairman of community development association, a female sociologist and a female psychologist. The qualitative participants were exempted from taking part in the quantitative aspect of the study. Five final year students of Sociology Department of the Lagos State University, comprising four men and one lady were engaged as assistants who conducted the in-depth interviews and administered copies of the questionnaire with the researcher. These assistants were rigorously trained on the techniques of interviewing people in ways that will prevent respondents from holding any vital information back. Pre-interview practice sessions were held to avail the research assistants the competence to administer questionnaire, handle tape recorders and transcribe their contents. These orientation exercises took five days. In all, one hundred and fifty copies of a questionnaire were administered, retrieved, correctly completed and analyzed for the study. For qualitative data, five in-depth interviews were conducted to elicit qualitative information about the nexus between adolescent drug use and criminal activities in Lagos State.

Participants were selected across varying socio-economic backgrounds within the study area. The survey covers the extent of the influence of drug use on the life chances of adolescents and the extent to which their subsequent activities threaten social order in Lagos State. Consent forms were administered to all the participants before the interview. The researcher safely keeps tapes, consent forms and notes taken during the in-depth interview. Returned questionnaires were subjected to thorough editing. Prior pre-coding of the questionnaire facilitated entry and analysis. Quantitative data collected from this survey were subjected to analysis at univariate, bivariate and multivariate levels. In addition, qualitative data were content analyzed. Ethnographic summaries were extracted from indepth interview to complement quantitative data and make report writing more factual and robust. Two correlation analyses were run to show the degree of relationship between dependent and independent variables. The first correlation was on ever used drug and independent variable which are the reasons for using drugs. Second, ever committed crime and reasons for committing crime were run together but were taken as individual variables. 


\section{Results}

The results consist of demographic variables and responses to the three research questions.

\section{Demographic Variables}

From Table 1, the age pattern of the respondents indicated that the proportion of respondents in age group 21-25 years is proportionally more than other categories $(26.7 \%)$. While $63.8 \%$ of the respondents were single, married $(28.3 \%)$, divorced $(3.3 \%)$, separated $(3.9 \%)$ and widowed $(0.7 \%)$. With $13.7 \%$ of the respondents having the first school leaving certificate, West African school certificate (55.5\%), Ordinary National Diploma (11.6\%), first degrees (8.2\%), National Certificate in Education (5.5\%), and masters degrees (5.5\%). Among respondents, there are more Christians than Muslims. Furthermore, $60.5 \%$ of the respondents are Christians, Muslims (34.0\%), traditional believers $(4.8 \%)$ and $(0.7 \%)$ belongs to others. The level of ethnicity did not deviate significantly from the expected pattern as $52.0 \%$ of the respondents are Yoruba, Hausas (17.1\%), Ibos (16.4\%) and others $(14.5 \%)$. Age is not a barrier to drug abuse in the study site as every age was involved in its illicit consumption. Culturally, young persons were not allowed to use drugs in the community. But with the advent of civilization and its complication by global technology, older people in traditional environments have lost their firm grip over their younger ones such that the latter now demand for greater independence to live their lives the way they desire. In the communities of Lagos where the study was conducted, the parents and community elders are still saddled with the traditional responsibility of ensuring that the younger members of the community behave well. This norm informed the involvement of members of different ages in the study because as stakeholders, the consumption of drugs and its concomitant effects impact the lives of community members, irrespective of ages. In Nigeria, every citizen who is 18 years old is legally an adult. He/ she does not require the permission of any elder to participate in empirical studies. Nevertheless, the ethical condition of obtaining their agreement prior to the conduct of the study was sought through consent approval form. The participants were assured that the study will guarantee their confidentiality and would not use the data provided in a way that will unduly expose their privacies. They were also informed that they could withdraw from participating should they become uncomfortable with the study. Majority of participants being single, having school certificates, Christians and Yoruba respondents has implications for the findings of this study.

\section{Reasons behind adolescents' abuse drugs}

Table 2 reveals that $65.2 \%$ of the respondents were hooked on drug taking between 10 and 18 years. The picture that these data paint about the mental health of future leaders, who are resident in Lagos State, is a matter for serious concern demanding urgent attention. No wonder that most contemporary adolescents no longer find it convenient and practicable to put customary respect on display for their elders, even in their traditional neighborhoods. This is a cause of frequent conflict among the younger and older generations of residents in the study site.

A female psychologist in-depth interview participant offered the following as an explanation:

Factors that predispose adolescents to drug abuse include broken homes, exclusion, frustration, imitation or peer pressure. More importantly, the backgrounds of drug users determine the factors that will be held responsible for predisposing them to specific drugs they abuse, the kind and level of violence the drug abusers are likely to put on display.

Table I Socio - demographic characteristics of respondents

\begin{tabular}{lll}
\hline Characteristics & Frequency & Percent \\
\hline Gender & 125 & \\
Male & 25 & 83.3 \\
Female & 100 & 16.1 \\
Total & & 100 \\
Age & 14 & \\
20 Below & 40 & 9.3 \\
$21-25$ & 30 & 26.7 \\
$26-30$ & 34 & 20 \\
$31-35$ & 15 & 22.7 \\
$36-40$ & 17 & 10 \\
$41-$ and above & 100 & 11.3 \\
Total & & 100 \\
Marital status & 97 & \\
Single & 43 & 63.8 \\
Married & 5 & 28.3 \\
Divorced & 1 & 3.3 \\
Widowed & 6 & 0.7 \\
Separated & 100 & 3.9 \\
Total & & 100
\end{tabular}

Education

$\begin{array}{lll}\text { FSLC } & 20 & 13.7\end{array}$

$\begin{array}{lll}\text { WASC } & 81 & 55.5\end{array}$

$\begin{array}{lll}\mathrm{NCE} & 8 & 5.5\end{array}$

$\begin{array}{lll}\text { OND } & 17 & 11.6\end{array}$

$\begin{array}{lll}\mathrm{BSc} / \mathrm{BA} / \mathrm{Bed} & 12 & 8.2\end{array}$

$\begin{array}{lll}\mathrm{MSc} / \mathrm{Med} & 8 & 5.5\end{array}$

$\begin{array}{lll}\text { Total } & 100 & 100\end{array}$

Religion

$\begin{array}{lll}\text { Christianity } & 89 & 60.5\end{array}$

Islam $\quad 50 \quad 34$

Traditional $\quad 4.8$

Others $\quad 1 \quad 0.7$

$\begin{array}{lll}\text { Total } & 100 & 100\end{array}$

Ethnic group

\begin{tabular}{lll} 
Ibo & 25 & 16.4 \\
Hausa & 26 & 17.1 \\
Yoruba & 79 & 52 \\
Others & 22 & 14.5 \\
\hline
\end{tabular}




\begin{tabular}{lll}
\hline Characteristics & Frequency & Percent \\
\hline Total & 100 & 100 \\
Occupation & & \\
Civil Servant & 21 & 13.9 \\
Private Sector Worker & 43 & 28.5 \\
Trader & 24 & 15.9 \\
Applicant & 19 & 12.6 \\
Others & 44 & 29.1 \\
Total & 100 & 100 \\
Place of residence & & \\
Lagos Island & 34 & 22.8 \\
Lagos Mainland & 38 & 25.5 \\
Suburb & 36 & 24.2 \\
Others & 41 & 27.5 \\
Total & 100 & 100 \\
\hline
\end{tabular}

Table 2 Adolescents drug use habit in lagos

\begin{tabular}{|c|c|c|}
\hline Characteristics & Frequency & Percent \\
\hline \multicolumn{3}{|l|}{ Time that drug use began } \\
\hline Under One Year & 13 & 9.8 \\
\hline $1-4$ years & 12 & 9.1 \\
\hline $5-9$ years & 21 & 15.9 \\
\hline $10-14$ years & 17 & 12.9 \\
\hline $15-18$ years & 69 & 52.3 \\
\hline Total & 100 & 100 \\
\hline \multicolumn{3}{|l|}{ Reasons for using drugs } \\
\hline Overcome Frustration & 34 & 24.6 \\
\hline Relieve Stress & 30 & 21.7 \\
\hline Forget Personal Sorrow & 38 & 27.5 \\
\hline To Get Along & 23 & 16.7 \\
\hline To Fight Loneliness & 13 & 9.4 \\
\hline Total & 100 & 100 \\
\hline \multicolumn{3}{|c|}{ Parents reaction on knowing that $i$ use drug } \\
\hline Spanked me & 25 & 22.5 \\
\hline Disowned me & 16 & 14.4 \\
\hline Drove me out of the house & 4 & 3.6 \\
\hline Encouraged me & 12 & 10.8 \\
\hline Discouraged me & 54 & 48.6 \\
\hline Total & 100 & 100 \\
\hline \multicolumn{3}{|l|}{ Parent use drugs } \\
\hline Yes & 25 & 29.1 \\
\hline No & 61 & 70.9 \\
\hline Total & 100 & 100 \\
\hline
\end{tabular}

\begin{tabular}{lcl}
\hline Characteristics & Frequency & Percent \\
\hline How drug using habit was picked & & \\
Personal Trials & 41 & 35 \\
Peer Influence & 54 & 46.2 \\
Through Siblings & 4 & 3.4 \\
From the Streets & 12 & 10.3 \\
Through Errand Running & 6 & 5.1 \\
Total & 100 & 100 \\
Number of times drug is consumed daily & \\
One & 40 & 29.2 \\
Twice & 35 & 25.5 \\
Trice & 13 & 9.5 \\
Many Times & 49 & 35.8 \\
Total & 100 & 100 \\
Markets from which drugs are procured & \\
Open Markets & 40 & 28.6 \\
Hideouts & 38 & 27.1 \\
Motor Parks & 10 & 7.1 \\
Mallam Stalls & 14 & 10 \\
Everywhere & 38 & 27.1 \\
Total & 100 & 100 \\
\hline
\end{tabular}

\section{Female IDI respondent January 8, 2012}

The study sample is composed of 125 male and 25 female drug users. This disproportionate gender representation in the sample is due essentially to multi-factoral causes. Among these, effects of traditional sex role socialization of the female to abstain from involvement in drug use outside those prescribed by experts. Thus, religion and societal expectations of the compliance of female gender with moral conduct are firmer than the male. Therefore, the observed gender disparity is in agreement with the cultural norm that forbids women's use of drug, in most communities, especially in a male dominated setting such as Lagos State, Nigeria. Majority of the indepth interview respondents agreed that men are guiltier of drug abuse than women. Critical analyses of the reasons that compel adolescents to use drugs against normative expectation reveal that they do not recognize gender boundary.

A male drug taking in-depth interview respondent also provided a window into the effects of his drug consuming adventure on him and the community:

I am not sure if my mother is not a prostitute. I discovered early in my life that no man lived with us but different men came to the one room shop apartment in which only my mother and I lived. Most of the time when these men came, at different times, my mother sent me out. It was my presence outside most of the time that exposed me to a friend who took me to the bus stop where older boys played the egg-breaking game called 'sukuliyan'. The winners requested us to 
market these broken eggs, on commission. This was how I started street life. Since nobody looked for me and the supposed 'home' was not homely, I decided to remain with my street family. As we grew older together, we tried different kinds of mind-blowing antics. We are known in most of the police stations as street boys. Many times, I have been sentenced to three and six months terms in prison because I stole. The place is better than outside as you had a place to sleep and people to ask after your health. I have never killed but I consumed gum, alcohol and raped a girl sometime ago. I am not sure I can be a human being like others. Where are the members of my family who could give me that sense of belonging?

\section{Male IDI Drug User respondent January 8, 2012}

The study found that marijuana belongs to the realm of the personal in Lagos due to its prohibition by the law and the disapproval of its use by the people. Private marijuana use is tolerated, but toleration is not the same as approval. The present study confirms the foregoing as $46.2 \%$ admitted that peer influence pressured them into drug use, personal trials $(35.0 \%)$, from the street $(10.3 \%)$, through errand running (5.1\%) and through siblings (3.4\%). Going by the above, it is clear that respondents got hooked up on drugs through diverse means which are primarily interactional.

A female consumer of drug who also is an in-depth interview respondent narrated her entry into drug consumption and the journey of her life thus far:

The absence of adults who could maintain discipline as I was growing up was the single most important cause of my drug taking habit. My parents left home for work every day leaving the siblings behind without any capable guardian. The independent atmosphere created by the absence of our parents offered us boundless opportunities to try all forms of habit. We started with mat smoking. We graduated into local dry gin theft and launched into stealing. One day, three of us left the home for the streets. We were doing our things together until a fight broke out over a man who slept with the three of us and decided to send two of us out to keep the third and the youngest. The other and I went our ways, leaving the one, who wanted to marry, remain with her husband. Over ten years now, I have not seen any of them or my family members. I have been arrested five times and jailed only once. I have committed abortion twice. I have no home to go and since there is no place to live and no skills to guarantee an employment, I have to continue my business, hoping that God will continue to protect me.

\section{Female IDI Drug User Respondent January 8, 20I 2}

A male drug abuser, who is also an in-depth interview participant, traced the history of how he became hooked on to drug and explained:

My drug taking habit took its roots from truancy. My parents are rich and caring but they are unpardonably negligent in their monitoring assignment as parents. After paying my school fee, they had no regard for what I did in school after leaving home. It was from the consumption of madras, which my friends considered to have a mind-blowing effect on them that attracted me into drug. From that they introduced me to a drug they called 'glutanporan'. They claimed it helped to cool the brain and stimulated the memory. This was how I irretrievably launched into drug abuse. Some friends too, who saw me as credible because my parents are rich, were also inadvertently misled into drug abuse. We all enjoyed the initial euphoria. It is indeed a new territory without the domineering influence of our parents.

\section{Female IDI Drug User Respondent January 8, 2012}

Data also established that $34.0 \%$ of the respondents attributed their use of drugs to helping them to overcome frustration, used it to forget personal sorrow $(38.0 \%)$, they relieve stress $(30.0 \%)$, used it to get along $(23.0 \%)$ and fight loneliness $(13.0 \%)$. To these young drug abusers, drug abuse is functional. To the extent that they could identify seemingly logical explanations about the good work which it does in their lives, they might not have been thumb-screwed into the habit without being conscious of both the intended and unintended implications of the drug abusing habit.

A fifteen-year-old-female drug abusing in-depth interview respondent examined the different functions which her drug abusing character performs said:

First and foremost, were it not for drugs that I use, I probably would have committed suicide long time ago. Or frustration surrounding my being would have killed me with hypertension. Imagine, when my only younger brother and my parents getting roasted in our house before I arrived from the school without anybody offering any explanation and assistance. For my first one week on the street, I lived as if I had lost my memory. It was when I started using drugs I got reconnected to reality. For bailing me out of that trauma, I cannot disengage from it. Drugs makes me rise above the falling rain, even though, at some costs. It gives me the courage to take daring actions that give me what I want without considering the side effects. For example, I make love to those who demand for it without considering whether or not they are good looking.

\section{Female IDI respondent January I I, 20 I 2}

Providing critical causative factors of drug abuse and locating majority of these factors in the abusers' network of interactions, a female sociologist in-depth interview respondent said:

Adolescents cannot be of superior moral value than the adult population that gave rise to them by birth and orientation. The facts of biology and socialization have critical roles to play in this. Critically looked at from the point of view of human relations, it is clear that there is something lopsidedly interactional about adolescents' adoption of sustenance abuse and its attendant criminal outcomes in Lagos State, as it might also be in other places. If government can enable social workers to partner with parents at homes, workers at religious institutions and teachers in schools, these professional care givers could restructure the relationship between adolescents and drug abuse in society.

\section{Female IDI respondent January 8, 2012}

\section{Implications of drug abuse for public safety in Lagos (Table 3)}

Reckless consumers of drugs indulge in the habit, most commonly not clearly conscious of the full implications of the habit in which they are investing the earlier parts of their lives and resources. Data in table 3 indicate that respondents funded their drug abuse habit from an assortment of sources as $74.3 \%$ of the respondents admitted they got money to buy drugs through doing menial works, pocket money from parents $(11.1 \%)$, alms $(8.1 \%)$, gift from relations $(5.1 \%)$ and theft $(1.5 \%)$. Nevertheless, the adolescent drug consumers acknowledged that their habit of drug abuse causes them to experience different kinds of losses as $42.5 \%$ of the respondents indicated financial losses, emotional $(17.3 \%)$, material $(14.2 \%)$, academic $(7.1 \%)$ and all the 
above (18.9\%). No matter how satisfying the abuse of drug may seem to appear, drug abusers have their silent worries about their drug abuse practices. The habit as can be seen above has different kinds of effects on the abusers, some of which cannot be reversed in their lives.

Table 3 Adolescents drug use management in lagos

\begin{tabular}{lll}
\hline Characteristics & Frequency & Percent \\
\hline \multicolumn{2}{l}{ How adolescent fund their drug use habit } & \\
Menial Works & 101 & 74.3 \\
Alms & 11 & 8.1 \\
Theft & 2 & 1.5 \\
Gift From Relations & 7 & 5.1 \\
Pocket Money From Parents & 15 & 11.1 \\
Total & 100 & 100
\end{tabular}

Kind of losses experienced by adolescent drug users

$\begin{array}{lll}\text { Financial } & 54 & 42.5 \\ \text { Material } & 18 & 14 . \\ \text { Emotional } & 22 & 17.3 \\ \text { Academic } & 9 & 7 . \\ \text { All of the Above } & 24 & 18.9 \\ \text { Total } & 100 & 10\end{array}$

Adolescents' drug use has criminal consequences

Yes 40

No 93

Total

100

100

Adolescent drug users' criminal activities

Successful

24

Unsuccessful

65

Total

100

27

100

Controls to adolescent drug users' criminal acts

Law Enforcement Agencies

43

Nothing

Total

Adolescent drug users fear the police

Yes

No

Total

100

100

Why adolescent drug users fear the police

Arrest

32

Use Part of Drug

28

Seize Drug

6

Beat Me

6

Total

2

100

Why adolescent drug users do not fear the police

\begin{tabular}{lll}
\hline Characteristics & Frequency & Percent \\
\hline Police are worse than me & 33 & 34 \\
They are drug users too & 50 & 51.5 \\
They are tolerant of drug use & 12 & 12.4 \\
They are tolerant of drug mongers & 2 & 2.1 \\
Total & 100 & 100 \\
Adolescent drug users ever committed crimes & \\
Yes & 40 & 31.7 \\
No & 86 & 68.3 \\
Total & 100 & 100 \\
Number of times arrested for criminal acts & \\
Once & 31 & 39.7 \\
Twice & 39 & 50 \\
More than twice & 8 & 10.3 \\
Total & 100 & 100 \\
\hline
\end{tabular}

The female sociologist in-depth interview participant examined drug abuse and identified some critical implications on individuals and society:

Adolescents are the hopes of the future community. When this critical component of the human population willfully wastes away, it is a matter of grave concern. On the individual, drug abuse leads to a waste of precious productive youth life, mismanagement of early reproductive resources, unwanted pregnancies, loss of focus and compromises the health of the abuser. At the community level, drug abuse increases deviant behaviour, violence, loss of personal belongings, homelessness, fear and panic as social order becomes its inevitable casualty.

\section{Female IDI respondent January 8, 2012}

A female drug user in-depth interview respondent lamented that:

The most painful effect of my habit of drug abuse is that it has caused me to miss my education. I broken the bond of family such that no member of the family wants to have anything to do with me because they claim I had violated the integrity of to the family. As a result of chain smoking, I now suffer from tuberculosis. Also, I have committed abortion five times in the hands of quack doctors. I am not sure I will be able to become pregnant and give birth to my own children. Who will even agree to marry me the way I am, in the first place. Can't you see that I look desolate? Beyond that, I am of no traceable family? Today, I am realizing I had wasted the early productive part of my life.

\section{Female IDI respondent January I 2, 20 I 2}

Another drug user, who is a male in-depth interview respondent, counted his blessing since he absconded from his family and weighed it against his losses and declared:

Apart from the fact that one looks very dejected as a consequence of suffering the sense of being excluded, I regret my drug abusing habit because the journey into the habit is more of curses than blessings to me. Sometimes, people look at me as if I am a lunatic. One cannot 
even spend all the fortunes one makes from crime on one's looks. The police collect a bulk of it and leave you after they know that you are without any money to continue another round of antisocial life. Now, medical examination has revealed that I have contracted HIV AIDs. Leaving the habit of drug abuse is of no use because this disease, according to medical doctors, requires some management, which I cannot afford.

\section{Male IDI respondent January I0,20I2}

Respondents admitted that abusing drug has negative collateral effects on them as they identified different consequences which they face. Regrettably, more of the respondents admitted that drug abuse has no criminal implications for their actions even when $73.0 \%$ of the respondents admitted that their criminal activities were usually unsuccessful. About $72.6 \%$ of the respondents said they did not fear the police and offered reasons which range from policemen are drug abusers too $(51.5 \%)$, police are worse than drug abusers $(34.0 \%)$, police are tolerant of drug abusers $(12.4 \%)$ and police are lenient with drug mongers $(2.1 \%)$. Adolescents may also continue to abuse drugs because the police are not responsible role models in society. If they are responsible, deviant youths will not have pointed accusing fingers at them even to the extent of claiming that the police too are drug abusers. Since the police abuse drugs in the company of these young citizens, they defy them because they have become partners in crime.

The male respondent of in-depth interview who also is the head of vigilante group observed:

Most adolescents go out at unearthly times. When we accost them, they usually provide spurious excuses. In some cases when searches were conducted on them, we found different kinds of drugs which ranged from Indian hemp, 'alomo', gum, other unidentifiable and tablets and capsules. Sometimes they were even in possession of dangerous weapons which suggested that they occasionally engaged in criminal activities.

\section{Female IDI respondent January 7, 2012}

In addition, the number of times respondents were arrested for criminal acts were variable. While $50.0 \%$ of the respondents confessed that they had been arrested for criminal activities twice, those who admitted it was once were $39.7 \%$ and those who were more than twice were $10.3 \%$. Arising from these data, there is a significant relationship between drug abuse and criminality among adolescents in the study site.

A male police officer who is also an in-depth interview participant talked about the injuries which drug abuse has caused some adolescent abusers:

As ordinary non-drug using individuals, these adolescents might not have been predisposed to criminality. But their drug abusing practices have emboldened them to ignore the reward for criminal activities and behave recklessly in the community. These young abusers cause significant panic for parents innocent children such that leaving these non-drug abusing children to move about independently becomes a serious challenge in the neighbourhood.

\section{Female IDI respondent January I 3, 20 I 2}

\section{Addressing the effects of adolescent drug abuse in society}

Data revealed that $70.0 \%$ of the respondents' parents did not use drugs. To that extent, the solution to the problem can still be found in the community. Since parents do not have hands in the drug socialization of children, their reactions on knowing that their children use drugs vary and they are symptomatic of responsible parenthood. About $48.6 \%$ of the respondents acknowledged that their parents discouraged them, spanked them $(22.5 \%)$, disowned them $(14.4 \%)$, encouraged them (10.8\%) and drove them out of the house $(3.6 \%)$. Much as it is understood that no parent who will be happy seeing his/her child taking to drug abuse, the action of those who disowned and evicted their drug abusing children is condemnable. Rather than becoming part of the solution, they were parts of the problem. To the extent that two wrongs never make a right, beheading someone who has a headache is not known anywhere as the most appropriate panacea.

A traditional ruler in-depth interview participant considered parent-children relationship visavis drug abuse and said:

Though, some parents mislead their children by their reckless lifestyles, most parents in Lagos, irrespective of their ethnic backgrounds, still believe that bad habits should be kept away from children. No sane parent who abuses drug will encourage his/her children to do the same thing. However, prostitutes have no values. They could indulge their children in any criminal practices. It is against this background that government should discourage prostitution or at least make prostitutes having babies a serious offence for practitioners. In the event they have, parents should adopt such children for proper upbringing.

\section{Female IDI respondent January 7, 2012}

A male police officer in-depth interview respondent looked at the issue of adolescent drug abuse differently:

Drug use among adolescent may become a way of life if they lack vigilant adults to monitor their activities. Most parents see alcohol use as a status conferring habit. In the quest of children to show that they also belong to a special genre of social beings to their friends, they abuse drugs, by erroneously taking it as status conferrers. Inadvertently, they may, as they often do, transit into crime except there are significant others who could manage them out of the eventual crises that they may experience. Otherwise, they inevitably become engaged with the criminal justice system.

\section{Female IDI respondent January 8, 20 I 2}

Data in table 2 attested to it that diverse markets exist in the community from which respondents obtained the drugs they abused as $28.6 \%$ of the respondents said they got their drugs from the open markets, hideouts $(27.1 \%)$, everywhere $(27.1 \%)$, mallam stalls $(10.0 \%)$ and motor parks $(7.1 \%)$. To the extent that there are accessible markets for the drug abusers to obtain their drugs, it may not be easy to discourage the habit.

To solve the problem associated with drug abuse, a sociologist indepth interview respondent observed:

Punishment for the operators of Drug Markets in the neighborhood should be as costly and painful as the one meted to drug abusers. Adolescents who can afford drugs have easy access to them because they are readily purchasable everywhere. Government should make drug sale and access difficult in the community to save the lives of children and the future of Nigeria. 


\section{Female IDI respondent January 9, 2012}

A male in-depth interview respondent who also is a Community Development Association chairman said:

The society as it is presently structured is experiencing a dearth of the kind of responsible mentors to rescue impressionable adolescents from the overwhelming influence of peer pressure in the neighborhood. Ours is a society in which politicians equip these adolescents with drugs and firearms to fight their real and perceived political adversaries. Since parents alone cannot ensure the production of responsible adolescents for future leadership positions in society, other child handling institutions such as schools, religious places, civil organizations should complement parents, in this regard, to handle the challenge more creditably.

\section{Female IDI respondent January 10, 2012 (Table 4)}

We ran the variables individually against ever used drugs so as to identify their relationships based on the previous studies, overcome frustration is significant and positive $\left(.214^{* *}\right)$ while relief of stress and to fight loneliness have positive relationship and are also significant.

\section{(Table 5)}

There is a negative relationship between the fear of police and ever committed crime $\left(-.381^{* *}\right)$. Potential criminals who use drugs do not see the police as deterrent role models. This facilitates crime commission. Those whose parents use drugs $\left(.159^{* *}\right)$ and the time drug consumption started $(.162 * *)$ and are significant.

Table 4 Correlation showing the relationship between ever used drugs and possible motivations

\begin{tabular}{lllllll}
\hline Ever used drug & Overcome frustration & Relieve stress & Forget sorrow & To fight loneliness & To get along & Ever used drug \\
\hline & 1 & $-.214^{* *}$ & $.186^{* *}$ & 0.088 & $.110^{*}$ & 0.096 \\
& 0 & 0 & 0.078 & 0.028 & 0.056 \\
& 100 & 100 & 100 & 100 & 100 & 100 \\
\hline
\end{tabular}

** Correlation is significant at the 0.01 level (2-tailed)

*Correlation is significant at the 0.05 level (2-tailed)

Table 5 Correlation showing the relationship between ever committed crimes and possible motivations

\begin{tabular}{lllllll}
\hline $\begin{array}{l}\text { Ever committed } \\
\text { crime }\end{array}$ & $\begin{array}{l}\text { Ever committed } \\
\text { crime }\end{array}$ & $\begin{array}{l}\text { Fear } \\
\text { police }\end{array}$ & $\begin{array}{l}\text { Means of } \\
\text { funding }\end{array}$ & $\begin{array}{l}\text { Parent used } \\
\text { drugs }\end{array}$ & $\begin{array}{l}\text { Time drug } \\
\text { started }\end{array}$ & $\begin{array}{l}\text { No of times drugs were } \\
\text { used }\end{array}$ \\
\hline 1 & $-.381 * *$ & 0.078 & $.159 * *$ & $.162 * *$ & 0.09 \\
& 1 & 0 & 0.117 & 0.001 & 0.001 & 100 \\
& 100 & 100 & 100 & 100 & 100 & 100 \\
\hline
\end{tabular}

**Correlation is significant at the 0.01 level (2-tailed)

*Correlation is significant at the 0.05 level (2-tailed)

\section{Discussion}

While participants' responses are uniformly distributed, it is clear that adolescents have a variety of reasons for abusing drugs. In this regard, the findings of this study are supported by Ericson's (1989:179) finding that the most commonly mentioned response was "relaxation, followed by euphoria, recreation, creativity, provides insights, pleasure and escapism". Though, anecdotal account has it that drug consumption causes crime, the extent to which this happens this way is inconclusive. For the foregoing, adolescents become less reliant on parental influences in making drug use decisions and turn instead to friends and peers. ${ }^{36,37}$ Moreover, though this study confirms various theories that suggest drug use develops from the interplay between social and personal factors, ${ }^{38}$ intoxication from alcohol might lead teenagers to start fights they otherwise would have avoided, and frequent use of alcohol might lead a temporarily sober teenager to commit robbery (i.e., to steal by force) to get money to buy more alcohol ${ }^{39}$ Furthermore, if at the ages of the respondents, the incidence of marriage pathology manifested as separation, divorce and widowhood, then drug abuse has implications for stable family system in the study site. Though data established that respondents showed a trend of ageing out of drug use and predictably criminality, the implications of the involvement of adolescent in drug abuse does not portend economic health for Lagos State. Age trends provide perspective on how the period of adolescence relates to the larger life span with regard to crime and substance use. Findings of this study substantially agree with Hirschi and Gottfredson's ${ }^{40}$ finding that in broad terms, rates of violent behavior and substance use follow the same age trend as almost all criminal or delinquent behaviors, with low levels up to the pre-teen years, a peak somewhere between mid-adolescence and early adulthood, and a continuous decline over the rest of the life span. Furthermore, illiteracy could possibly not be advanced as a justification for adolescents' lure into drug use and consequent criminal misconduct in Lagos State judging by the educational profile of the respondents. Also, to the extent that only less than one percent of the respondents did not belong to any particular religious group which is commonly assumed to be the devil that stirs criminality in Nigeria, this confirms that religiosity has no significant deterrent impact on both drug abuse and criminality in Lagos State. Data also show that drug use and attendant criminality are no respecters of ethnic boundaries in the study site. Data showed that while some parents were disappointed and took varying sanctions against their children, some respondents admitted that their parents encouraged them. This underscores the declining moral value in the contemporary society in which some parents have lost complete control over the cultural guidance of their children. Data revealed that the study site is not efficiently policed as drugs which adolescents commonly abuse are obtainable everywhere in the neighborhood. Judging by the revelation made by this study, there is congruence between the procedure of adolescent entry into drug abuse and earlier 
studies. There was a tendency to abuse the more illicit substances in the late adolescent period. It has been noted that adolescents that abuse substance become increasingly involved as they get older. ${ }^{41}$

Findings in the present study did not confirm the above. Nevertheless, the present study noted a frequency of multiple substance use among late adolescent age group, their consumption declined with age contrary to the foregoing. This may be due to decreasing peer influence, a culture that invades the privacy of the adolescent and conscious preparation by adolescents themselves for an engagement with marriage. It should be noted that parents who drove their adolescent children out of the house because of their drug abusing character are inadvertently becoming part of the problem rather than solution. Evicting children from home increases the number of street children, swells homelessness as well as have a multiplier effect on the number of children who may be vulnerable to criminality.

\section{Conclusion}

In wrapping up, besides crime and drug use being major public health challenges, the group that is most vulnerable to drug abuse is that which could most objectively be regarded as the drivers of Lagos' economy in the foreseeable future. It is along this line that public policy has to compel the investment of appropriate intellect, social resources and a range of other resources to rescue these at risk population from being consumed by the deadly social conditions to which drug abuse have the capacity to expose them. While this study may not be sufficient to make generalisable predictions on the nexus between adolescents, drug abuse and criminality, it does point to a significant decisive pattern in drug consuming habit of adolescents in Lagos. The socioeconomic and political location of Lagos makes it not well protected from the challenges of drug and drug abuse. As a result, its youth must be provided jobs and relaxation resources that could lower their frustration such that the patronage of drugs as temporary means of escape from disappointing realities would no longer be attractive and irresistible. Consequently, this paper calls for further research to adequately understand the impact of drug use in Lagos particularly and Nigeria in general. Although the use of drugs is not entirely new in Lagos, its current prevalence does not only raise some public health, social welfare and law enforcement concerns to policy makers and executors, it now bothers the household and causes health threatening fright to residents of Lagos. ${ }^{42-45}$

\section{Recommendations}

1. To reduce adolescents' drug abuse induced trauma in society, the present study suggests that:

2. Indigenous child socialization that emphasizes the concept of 'Omoluabi' meaning gentleman should be reintroduced, strongly articulated and put into use.

3. Indiscriminate drug economy and its patronage should be discouraged by law in Lagos.

4. Government should embrace community based drug abuse control and behavior monitoring of adolescents.

5. Public policy should empower social workers to partner with parents, teachers and workers at religious places in the socialization of adolescents to embrace lives that do not tolerate drug abuse so as to ensure public safety and future sanity of Nigerian youths. ${ }^{46,47}$

\section{Acknowledgement}

None.

\section{Conflict of interest}

None.

\section{References}

1. Fadayomi TO, Poukouta P. African Population perspectives and the Challenges for the 21 st Century. Durban Conference Report. 1999;4:31-145.

2. Makinwa Adebusoye P. Population and sustainable development in Africa: Issues for the 21 st century. Durban Conference Report. 1999;4:89-113.

3. Baker J. Juveniles in Crime Part 1:Participation rates and risks factors. NSW Bureau of Crime Statistics and Research and NSW Crime Prevention Division: Sydney. 1998.

4. Flowers RB. Drugs, Alcohol and Criminality in American Society. North Carolina: McFarLand \& Company. London:1999:1-57.

5. National Center on addiction and Substance Abuse. Adolescence and alcohol, tobacco and other drugs: A dangerous mix. New York: 1997.p. $1-419$.

6. Salmelainen P. The correlates of offending frequency: A study of juvenile theft offenders in detention. NSW Bureau of Crime Statistics and Research. Australia;1995:1-88.

7. Trimboli L, Coumarelos C. Cannabis and Crime: Treatment programs for adolescents cannabis use. Lawlink NSW: B41.Australia:1998;1-21.

8. Watters JK, Reinarman C, Fagan J. Causality, context, and contingency relationships between drug abuse and delinquency. Contemporary Drug Problems. 1985;12(3):351-373.

9. Fishbein DH. Boston. The Dynamics of Drugs. AbeBooks.USA:1996.

10. Kendall DE. Sociology in Our Times. Thomson \& Wadsworth. Texas:2001:1-35.

11. Hawkins JD, Lishner D, Catalano RF. Childhood predictors and the prevention of adolescent substance abuse. In CL Jones \& RJ Battjes, editors. DHHS Publication ADM. Washington:1985;85-1335.

12. Alagbe R. Dangers of Drug Abuse among Youth. USA:2004.

13. Hawkins JD, Catalano RE, Miller JY. Risk and Protective Factors for Alcohol and Other Drug Problems in Adolescence and Early Adulthood: Implications for Substance Abuse Prevention. Psychol Bull. 1992;112(1):64-105.

14. Yamaguchi K, Kandel DB. Patterns of Drug Use from Adolescent to Young Adulthood: Sequence of Progression. American Journal of Public Health. 1984;74(7):673-681.

15. Jaffe JH. Drug Addiction and Drug Abuse in Gilman. In: AS Rall, P Taylor, editors. The Pharmacological Basis of Therapeutics. New York:1991. p. 9-13.

16. National Drug Law Enforcement Agency. Drug Data Collection. Lagos: NDLEA. Nigeria:1992;1-36.

17. Chaiken J, Chaiken, M. Drug use and predatory crime. In J.Q. Wilson,M. Tonry Editors. Drugs and crime - crime and justice: An annual review of research Chicago, IL: University of Chicago Press. 1989;13. 
18. Goldstein P. The Drugs/Violence Nexus: A Tripartite Conceptual Framework. Journal of Drug Issues. 1985;15(4):493-506.

19. Oser C, Mooney J, Staton Tindall M, et al. The drugs-violence nexus among rural felony probations. $J$ Interpersonal Violence. 2009;24:1285-1303.

20. National Institute on Drug Abuse. Cocaine abuse and addiction.USA 2004.

21. Misuse of Prescription Drugs. Abuse and addiction.USA. 2005.

22. Methamphetamine. National Institution on abuse and addiction. USA 2006.

23. Rodriguez N, Katz C, Webb VJ, et al. Examining the impact of individual, community, and market factors on methamphetamine use: A tale of two cities. Journal of Drug Issues. 2005;35(4):665-694.

24. Blum R. Contemporary threats to adolescent health in the United States. JAMA. 1987;257(24):3390-3395.

25. Abudu V. Young People and Drugs Abuse. Being a paper presented at the 8th biennial International conference on alcohol, drugs and society in Africa, Abuja, Nigeria between 23rd - 25th July. Africa:2008;1-11.

26. Adams, Edgar H, Blanken A et al. Overview of selected drug trends Rockville, MD: National Institute on Drug Abuse. 1990

27. Oshikoya KA, Alli A. Perception of Drug Abuse Amongst Nigerian Undergraduates. World Journal of Medical Sciences. 2006;1(2):133139.

28. Khantzian EJ. The self-medication hypothesis of addictive disorders: Focus on heroin and cocaine dependence. Am $J$ Psychiatry. 1985;142(11):1259-1264.

29. Collins J J. Drinking and crime. Guilford Publications. New York;1993;1-13.

30. Collins AC. Genetics as a tool for identifying biological markers of drug abuse. In: Braude MC, Chao HM, editors. Genetic and Biological Markers in Drug Abuse and Alcoholism. American Psychiatric Association Publishing. USA: 1986;57-70.

31. White HR. The drug use-delinquency connection in adolescence. In Drugs, crime, and criminal justice. Cincinnati: Anderson Publishing Company. 1990;1-385.

32. White HR, Hansell S, Brick J. Alcohol use and aggression among youth. Alcohol Health Res. 1993;17(2):144-50.

33. Campbell J. This Is Africa's New Biggest City: Lagos, Nigeria, Population 21 Million. Retrieved on June 8, 2014 from /this-is-africas-
new-biggest-city-lagos-nigeria-population-21-million/259611/The Atlantic (Washington DC). 2012.

34. Rice X. Nigeria's commercial capital's size, its economic importance, and its government's energy in addressing concrete urban problems. Financial Times in Campbell J. This Is Africa's New Biggest City: Lagos, Nigeria, Population 21 Million.2012.

35. Gravetter FJ, Forzano LB. Instructor's manual with test bank for research methods for the behavioural sciences. Belmont, Wadsworth, editors. 5th ed. New York: Test bank, 2003.

36. Miller MA, Alberts JK, Hecht, et al. Adolescent relationships and drug use. Lawrence Erlbaum Associates Publishers. US:2000.

37. Newcomb MD. Psychosocial predictors and consequences of drug use: A developmental perspective within a prospective study. Journal of Addictive Diseases. 1997;16(1):51-89.

38. Botvin GJ, Malgady RG, Griffin KW, et al. Alcohol and marijuana use among rural youth: Interaction of social and intrapersonal influences. Addict Behav.1998;23(3):379-387.

39. Osgood DW. Drugs, Alcohol and Adolescent Violence. Boulder: Centre for the Study and Prevention of Violence Institute of Behavioural Science. USA, 1998;153-192.

40. Hirschi T, Gottfredson M. Age and the explanation of crime. American Journal of Sociology, 1983;89:552-584

41. Abiodun OA, Adelekan ML, Ogunremi OO, et al. Pattern of substance use among secondary school students in Ilorin, Nigeria. West African Journal of Medicine. 1994;13(2):91-97.

42. Lagos State Government Population. Lagos State Government 2011. Nigeria:2011;1-167.

43. Fagan J. Intoxication and aggression in drugs and crime. In Crime and Justice: A Review of Research. M. Tonry, JQ Wilson, editors. Chicago press. 1990;13:241-320.

44. National Agency for Food and Drug Administration and Control. (NAFDAC). In: Omadjohwoefe OS. Drug Prohibition and the Problem of Conformity in Nigeria. Journal of Psychology. 2010;1(2):91-97.

45. Nephalim B. Drug Prohibition. Premier on Drugs. 2005;4(1):9-21

46. Omadjohwoefe OS. Drug Prohibition and the Problem of Conformity in Nigeria. Journal of Psychology. 2010;1(2):91-97.

47. Omigbodun OO, Babalola O. Psychosocial Dynamics of Psychoactive Substance Misuse among Nigerian Adolescence. Annals of African Medicine. 2004;3(3):61-69. 